\title{
Performance Quality Testing under Combined Loading of Polyethylene Pipes Reinforced with Aramid Fiber
}

\author{
Hilario Hernández-Moreno ${ }^{1}$, Erik Vargas-Rojas ${ }^{1}$, Víctor Manuel Sauce-Rangel ${ }^{1}$, Iván Mortera-Bravo ${ }^{2}$, Jorge Luis \\ González-Velázquez ${ }^{2}$, Maarten P. Kruijer ${ }^{3}$ and Margarita Navarrete-Montesinos ${ }^{4}$ \\ 1. ESIME (Escuela Superior de Ingeniería Mecánica y Eléctrica) Unidad Ticomán, Instituto Politécnico Nacional, Distrito Federal \\ 07340, México
}

2. ESIQIE (Escuela Superior de Ingeniería Química e Industrias Extractivas), Instituto Politécnico Nacional, Distrito Federal 07300, México

3. Department of Research \& Development, Pipelife Netherlands B.V., Enkhuizen, P.O. Box 380; 1600 AJ, The Netherlands

4. Instituto de Ingeniería, Universidad Nacional Autónoma de México, Distrito Federal 04510, México

Received: May 19, 2014 / Accepted: June 05, 2014 / Published: August 25, 2014.

\begin{abstract}
This paper presents the results of the performance quality testing of polyethylene pipes reinforced with aramid fibers, intended for applications such as discharging and gathering oil pipelines, and describes the test rig specifically designed for this purpose. The pipe specimens are submitted to impact with a device that simulates the collision of a pickaxe, and of a backhoe loader. After the impact, the pipes are tested under combined loading comprising internal pressure, and transverse loading; some pipe specimens without previous impact are tested as well. The results show that the reinforced thermoplastic pipes can fully withstand maximal operating pressure levels in the presence of damage and additional transverse loading.
\end{abstract}

Key words: Combined pressure-bending testing, oil industry, reinforced thermoplastic pipe, composite materials.

\section{Introduction}

Discharge and gathering oil pipelines are feasible to be affected by several forms of damage due to corrosion, complex loading, falling rocks, terrain movements and human activities like construction or agriculture that could strike them and inducing indeed mechanical damage. Metallic pipes are particularly susceptible to these kinds of aggressions, so the oil industry is looking into non-metallic solutions to cope with these problems. In order to certify the capability of non-metallic pipes, it is necessary to conduct a series of mechanical tests that simulate these harsh operating conditions. In this research, a non-metallic composite pipe or RTP (reinforced thermoplastic pipe)

Corresponding author: Jorge Luis González-Velázquez, Ph.D., research fields: mechanical metallurgy, fracture mechanics, corrosion, microstructural control and composites for oil industry. E-mail: jlgonzalezv@ipn.mx. is made of an inner and an outer pipe fabricated with HDPE (high density polyethylene), and an internal tape that consists of aramid cords that are embedded, but not impregnated by the HPDE [1].

Many studies related to thermoset composite pipes [2-6] have been published considering combined loads, as well as thermoplastic pipes [7]. However, there are few works relaying on RTP under combined load testing; in two of them, Kruijer et al. [8] investigated polyethylene pipes reinforced with embedded aramid fibers so as to identify its torsion-extension coupling, and the viscoelastic behavior of steel reinforced thermoplastic (polyethylene) pipe or s-RTP. With regards to test methods, Alexander [9] develops a series of full-scale tests on metallic repaired off-shore raisers using composites comprising pressure, pressure-tension, and pressure-bending tests, and develops a combined four point flexural device in 
which load is applied by means of two hydraulic rams. Corona and Kyriakides [10] reported an experimental procedure to evaluate buckling behavior under external pressure and bending.

Regardless of the fact that there is an important amount of research that has been conducted lately on the study of thermoset-composite pipes, there are no standardized tests intended for RTP that simulate combined loading encountered in real service conditions. This situation leads to evaluate the load capacity of the new type of thermoplastic reinforced pipes under harsh conditions encountered at on-shore applications. So, in order to fulfill this requirement, a series of tests are specifically developed to simulate extreme operating conditions such as combined flexural-pressure testing of undamaged specimens; and flexural-pressure testing of pipes previously stricken forcefully arising two kinds of damages: one that simulates a pickaxe tool, and the impact produced by a backhoe loader. The series of verification tests are performed on pipe samples bent to a bending radius of $1,500 \mathrm{~mm}$.

The paper is organized as follows: Section 2 describes the test specimens under study; Section 3 presents the non-standardized tests considered; Section 4 describes the testing setup in detail, comprising the conditioning of the test specimens, the impact testing devices, and the pressure-flexure testing; Section 5 presents and analyzes the results of the previous tests in terms of the measured parameters: time, internal pressure, load applied onto the RTP, and displacement during the flexure test; finally, Section 6 gives the conclusions.

\section{Pipe Description}

The aramid reinforced polyethylene pipes fabricated by Soluforce have a nominal diameter of $127 \mathrm{~mm}$ (Ø5"), and are composed of four layers (Fig. 1). The first layer is a thick polyethylene liner covered with two embedded, but not-impregnated aramid (Twaron) layers, each one composed of aramid rovings ducted

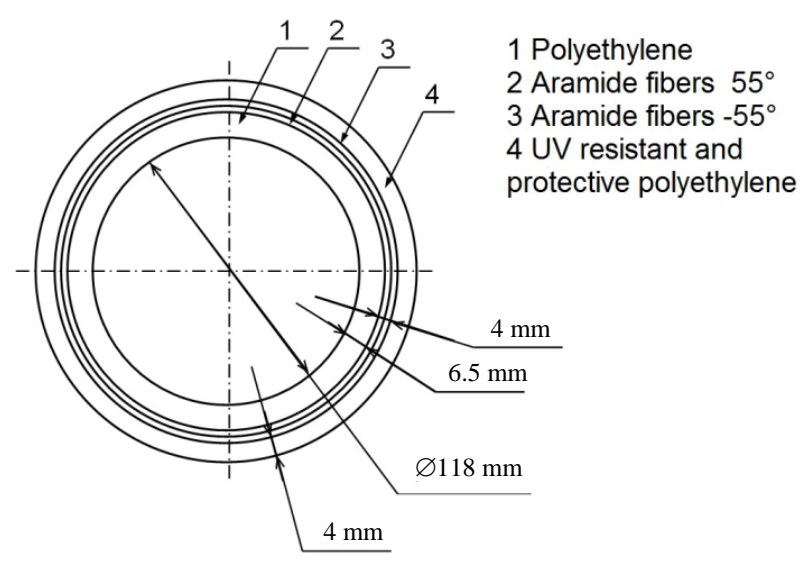

Fig. 1 Schematic cross section of a RTP pipe.

within polyethylene bands, with orientations of $+55^{\circ}$ and $-55^{\circ}$ with respect to the pipe axis. The last layer is a polyethylene protection layer treated with UV-resistant additives.

\section{Improved Acquisition}

In order to evaluate the pipe load bearing capacity to transport hydrocarbons safely, a series of non-standardized tests that simulate harsh operating conditions are proposed: three pipes receive an impact equivalent to $14 \mathrm{~J}$, simulating a pickaxe; three other pipes are impacted with a $124 \mathrm{~J}$ strike, simulating a backhoe loader. Then all the struck pipes are tested under combined flexure-pressure to simulate adverse conditions, and three others as in fabricated condition.

\section{Test Setup Description}

\subsection{Specimens and Conditioning}

The test specimens have a total length of 1,990 mm and are machined at both ends according to manufacturer specifications, so as to remove the aramid reinforcement layers and the protective polyethylene layer leaving a $50 \mathrm{~mm}$ length of nude polyethylene liner at both ends, so a couple of hermetic closures can be installed. Conditioned specimens are shown in Fig. 2.

\subsection{Impact Testing That Simulates a Pickaxe Tool Damage}

In order to develop the impact testing, the equivalent energy for the specific event is estimated to 


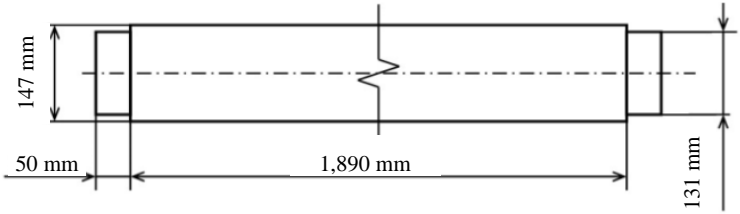

(a)

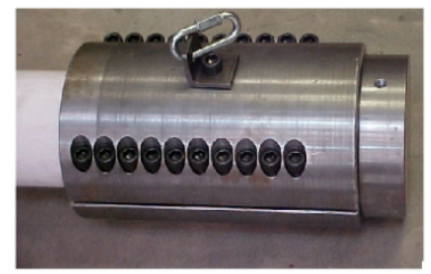

(b)

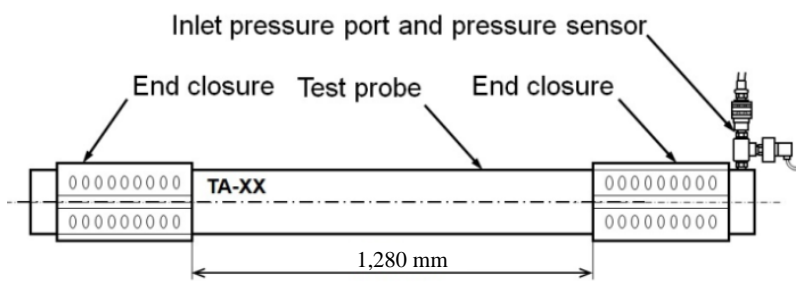

(c)

Fig. 2 Specimens and conditioning: (a) raw specimen; (b) end closures and (c) conditioned specimen.

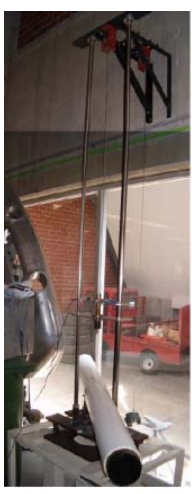

(a)

Fig. 3 Impact rig for simulating hand tool damage: (a) photograph and (b) schematic diagram.

be $14 \mathrm{~J}$. The device used for this test is available at the Engineering Institute of UNAM (Universidad Nacional Autónoma de México), and it consists of a free fall impact tester as shown in Fig. 3; it has a falling mass of about $6.8 \mathrm{~kg}$ and an impact spherical head of $\varnothing 10 \mathrm{~mm}$.

The calculated energy is measured with an accelerometer connected to a data acquisition card and a PC. Then, the necessary height to obtain a final speed of $2 \mathrm{~m} / \mathrm{s}$ at the moment of the impact can be calculated; all specimens for this test are as in fabricated condition except for their machined ends.

\subsection{Impact Testing That Simulates a Backhoe Loader Machine Damage}

The experimental device for this test is an impact test machine developed at IPN-ESIME (Instituto Politécnico Nacional- Escuela Superior de Ingeniería Mecánica y Eléctrica) Unidad Ticomán, which is also conceived as a free fall impact tester. In order to obtain the required energy for this impact, the height for the test was obtained by trial and error using an accelerometer and a data acquisition card connected to a PC until the final speed of $4 \mathrm{~m} / \mathrm{s}$ is reached. In Fig. 4 , a photo of the device and a schematic diagram are presented.

\subsection{Combined Loads Testing: Pressure and Flexure}

In order to implement these tests, the experimental setup consists of an universal mechanical testing machine model Instron 8502, and a specifically designed three point bending test device installed onto the actuator head. The conditioned specimen with its end closures, and the required hydraulic connections are placed over the flexural rig (Fig. 5). Both the specimen and the flexural rig are surrounded with a transparent protective barrier supported with metallic stiffeners. The flexural beam is a commercially available C-shaped cross section aligned horizontally.

Pressurization is carried out using water by means of two independent hydraulic circuits which operate alternatively. The main circuit is under high pressure and is used when the testing is running; the secondary circuit is low pressure, and is used for replenishment and drain. The high pressure is supplied by a positive-displacement, reciprocating pump specifically designed for this test, operated with a Shimadzu electromechanical universal testing machine. The hydraulic setup is depicted in Fig. 6.

The measured parameters are the flexure load, the displacement of the actuator of the Instron testing machine, and the specimen internal pressure. The Instron machine control unit provides several analog outputs; in this case two of these ports are used to 


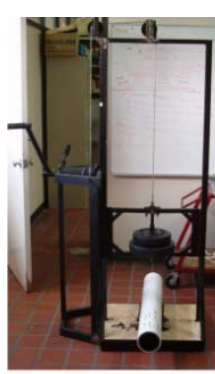

(a)

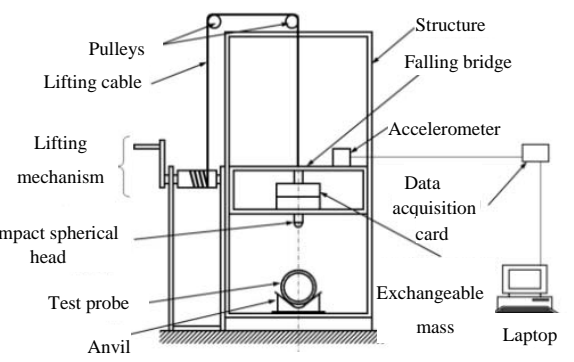

(b)
Fig. 4 impact tester for simuaung backhoe loader machine damage: (a) actual device and (b) diagram.

(a)
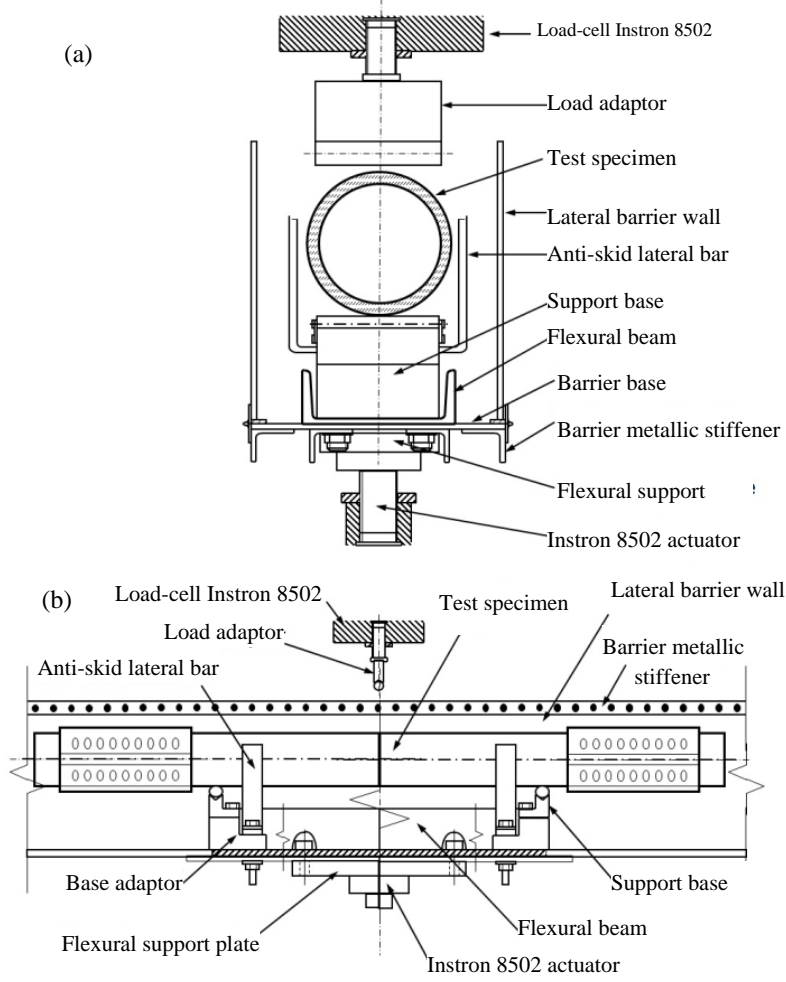

Fig. 5 Flexural setup: (a) lateral view and (b) cross section.

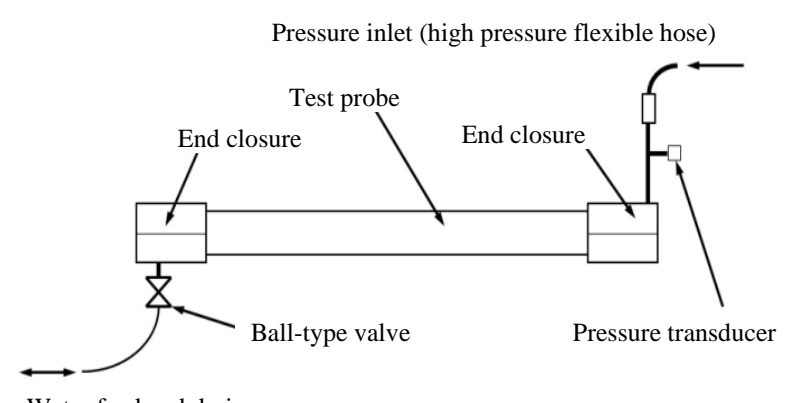

Water feed and drain

Fig. 6 Hydraulic circuits for combined pressure-flexure testing.

output the flexural load signal and the actuator displacement signal. To obtain the pressure signal, a voltage modulated signal transmitter is used. All signals are acquired using a data acquisition card connected to a notebook computer via a USB (universal serial bus) port. In Fig. 7, the instrumentation explicative diagram is presented.

To run the test, hydraulic pressure is increased up to 100 bar, which is the maximum operating pressure specified by the manufacturer of the pipes, with a pressure slope of $10 \mathrm{bar} / \mathrm{min}$. Once the pressure is reached and after verifying that hermeticity is assured, the hydraulic actuator moves at $10 \mathrm{~mm} / \mathrm{min}$ until a bending radius of $1,500 \mathrm{~mm}$ of the specimen is reached, equivalent to an actuator displacement equal to $60 \mathrm{~mm}$. Once the combined pressure and flexure condition are obtained, they are sustained for not less than $1 \mathrm{~min}$, then the flexure load is released, and the specimen is depressurized. During all this steps, displacement, flexure load and pressure signals are acquired at a rate of $1 \mathrm{~Hz}$; this rate is judged acceptable because the test is considered as in a quasi-static condition. The ideal pressure and displacement profile is depicted in Fig. 8, and photographs of the actual test are shown in Fig. 9.

\section{Results and Discussion}

\subsection{Impact}

The impact test profiles shown in Fig. 10 consist of an acceleration increment until an approximate value of $-7 \mathrm{~m} / \mathrm{s}^{2}$; under frictionless and dragless ideal conditions, this value should be the acceleration due to

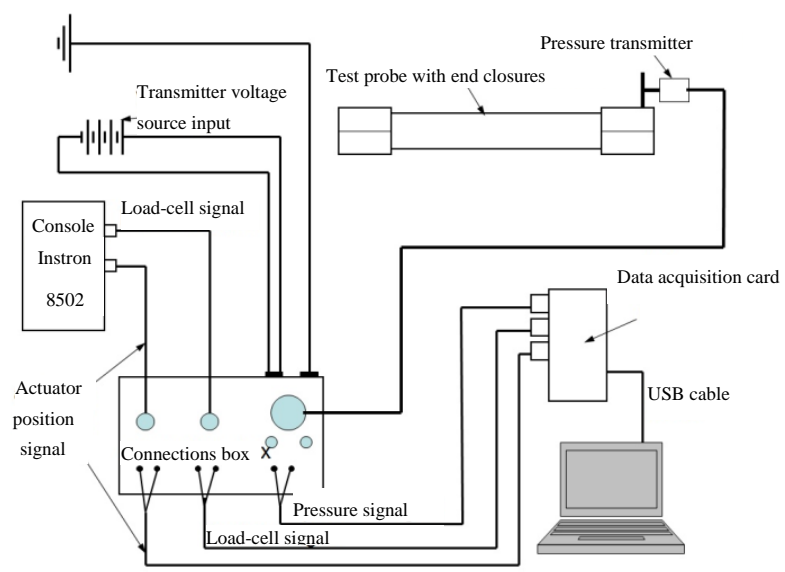

Fig. 7 Instrumentation required for pressure-flexure testing. 


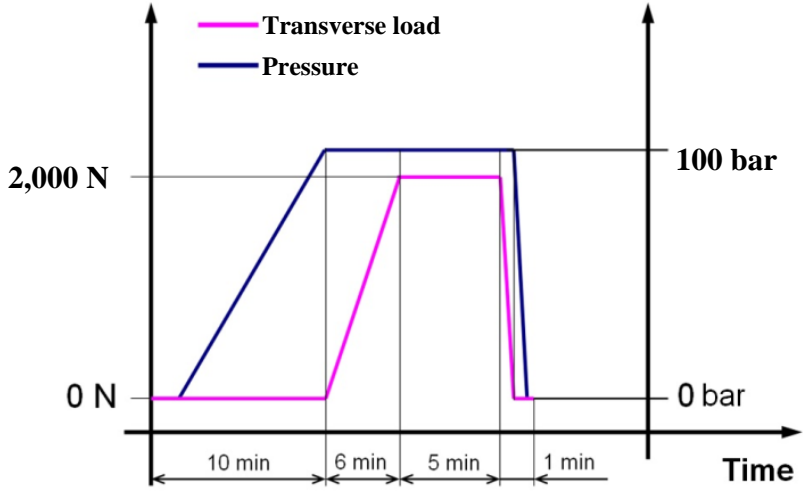

Fig. 8 Ideal pressure and displacement profile.

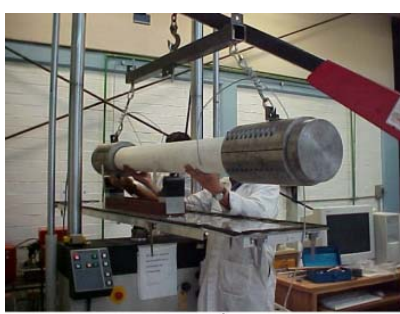

(a)

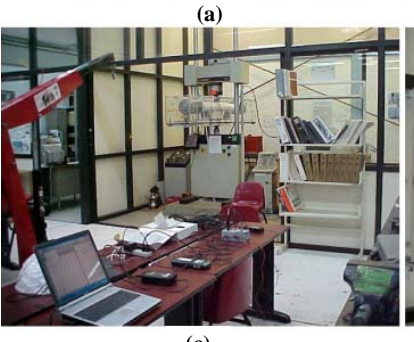

(c)

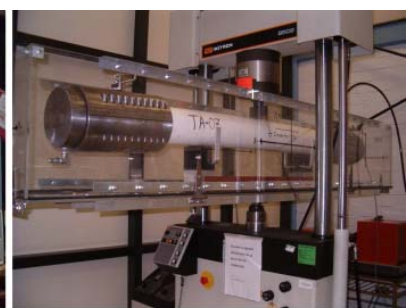

(b)

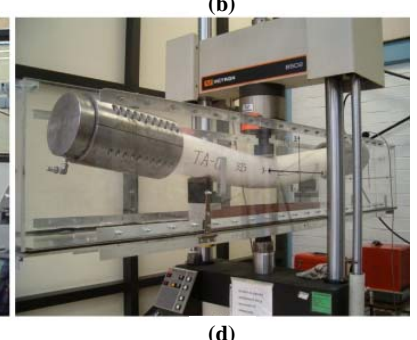

Fig. 9 Combined flexure-pressure test: (a) test setup; (b) specimen to be tested; (c) instrumentation and (d) specimen under combined flexure and pressure condition.

gravity. After this acceleration limit, a rapid change in acceleration is observed corresponding to the instant when the specimen is impacted; finally a region of several peaks is observed, corresponding to a series of rebounds after the impact, however, they are neglected. Thus, Figs. 10a-10c show the experimental graphs of the $2 \mathrm{~m} / \mathrm{s}$ impact test; in Figs. 11a-11c, the $4 \mathrm{~m} / \mathrm{s}$ test results are presented. The condensed results are shown in Table 1 (speed at impact and kinetic energy).

\subsection{Impact Damage Morphology}

The damages produced in all pipes owing to the 2 $\mathrm{m} / \mathrm{s}$ impact test show a spherical segment with an 8 $\mathrm{mm}$ diameter mark, as it can be observed in Fig. 12a. The damage due to the impact at $4 \mathrm{~m} / \mathrm{s}$ has also a spherical mark of about $12 \mathrm{~mm}$ in diameter, but
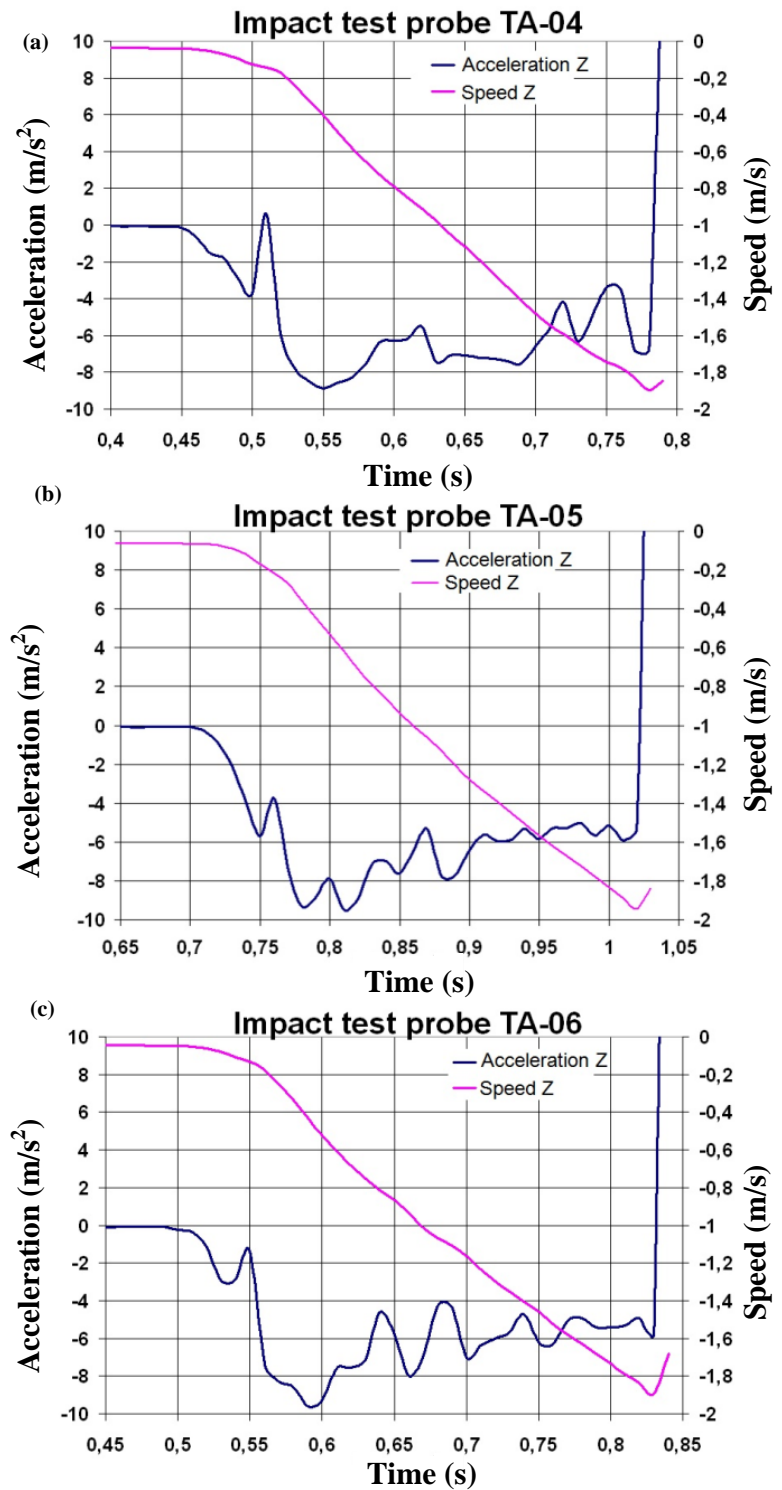

Fig. 10 Specimen acceleration and speed profiles: (a) TA-04; (b) TA-05 and (c) TA-06.

presents some additional marks caused by the rebounds after impact, as can be seen in Fig. 12b. Afterward, during the combined pressure and flexure loading, these marks tend to reduce their deformed shape and to move closer towards the median surface of the shell.

\subsection{Combined Pressure-Flexure Results}

The numerical treatment of the recorded data of nine tests is done for each type of test: specimens without damage, specimens previously impacted at 2 $\mathrm{m} / \mathrm{s}$, and specimens previously impacted at $4 \mathrm{~m} / \mathrm{s}$. The 

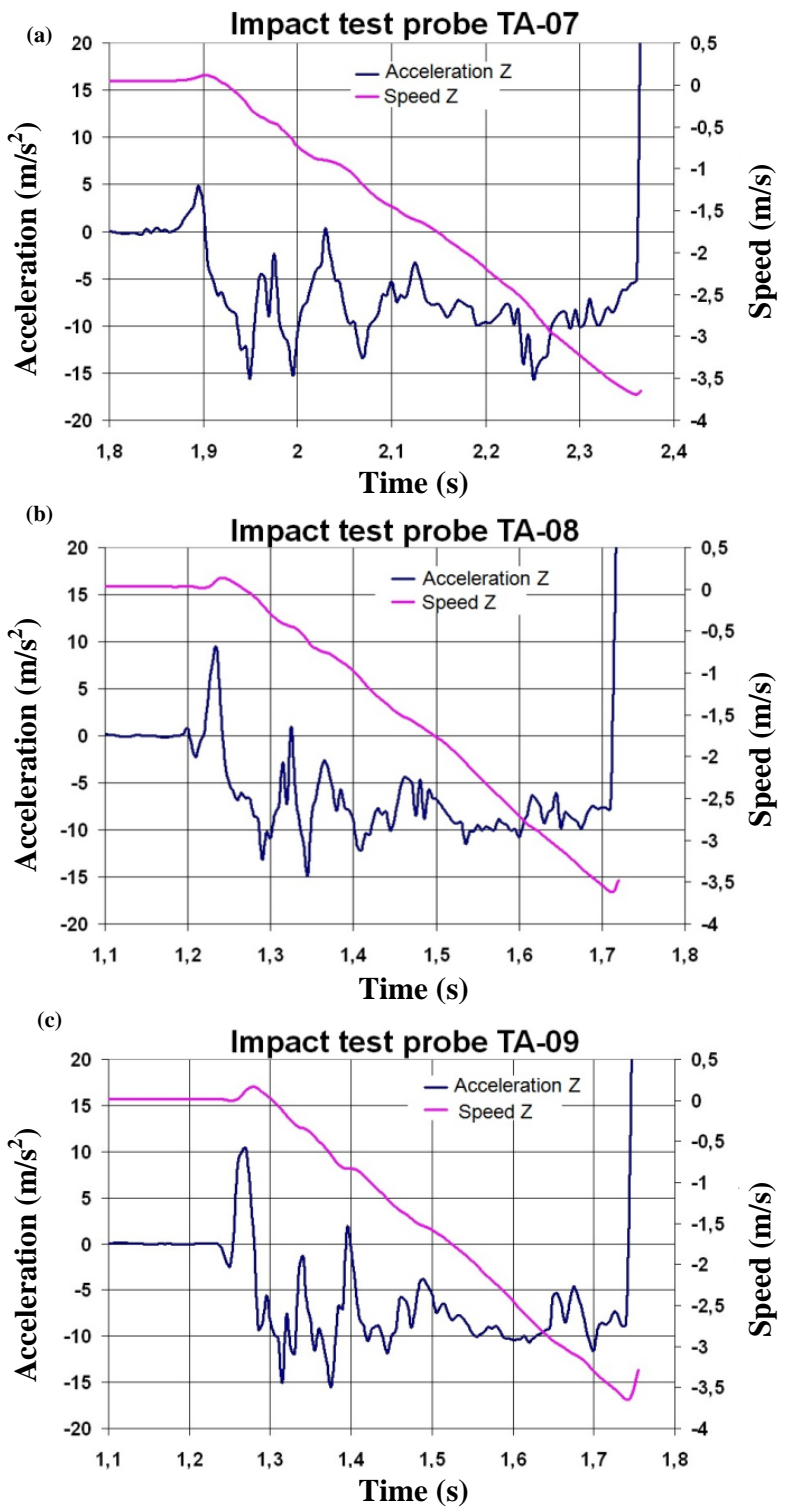

Fig. 11 Specimen acceleration and speed profiles: (a) TA-07; (b) TA-08 and (c) TA-09.

final results are presented as graphs of pressure-time in Fig. 13, load-time in Fig. 14, and load-displacement Fig. 15. All the results corroborate that the specimens behavior themselves as a whole structure or an end product, showing geometry, dimensions, materials and construction parameters, should be taken into account, not only representing material properties.

\subsubsection{Pressure as a Function of Time}

In this case, pressure corresponds to an excitation parameter. Experimental profiles of pressure-time show a sawtooth profile, as expected after using a reciprocating water pump to feed the system. The first
Table 1 Condensed impact test results.

\begin{tabular}{|c|c|c|}
\hline \multicolumn{3}{|c|}{ Impact simulating hand tool damage } \\
\hline Specimen & Impact speed (m/s) & $\begin{array}{ll}\begin{array}{l}\text { Maximum kinetic } \\
\text { energy }(\mathrm{J})\end{array} & \\
\end{array}$ \\
\hline TA-04 & 1.9 & 12.2 \\
\hline TA-05 & 1.9 & 12.9 \\
\hline TA-06 & 1.9 & 12.2 \\
\hline Mean & 1.9 & 12.4 \\
\hline Standard deviation & 0.03 & 0.38 \\
\hline $\begin{array}{l}\text { Coefficient of } \\
\text { variation }\end{array}$ & 0.015 & 0.030 \\
\hline \multicolumn{3}{|c|}{ Impact simulating backhoe loader machine } \\
\hline Specimen & Impact speed (m/s) & $\begin{array}{ll}\begin{array}{l}\text { Maximum } \\
\text { energy }(\mathrm{J})\end{array} & \text { kinetic } \\
\end{array}$ \\
\hline TA-07 & 3.7 & 46.5 \\
\hline TA-08 & 3.6 & 44.3 \\
\hline TA-09 & 3.6 & 45.1 \\
\hline Mean & 3.7 & 45.3 \\
\hline Standard deviation & 0.04 & 1.09 \\
\hline $\begin{array}{l}\text { Coefficient of } \\
\text { variation }\end{array}$ & 0.012 & 0.024 \\
\hline
\end{tabular}

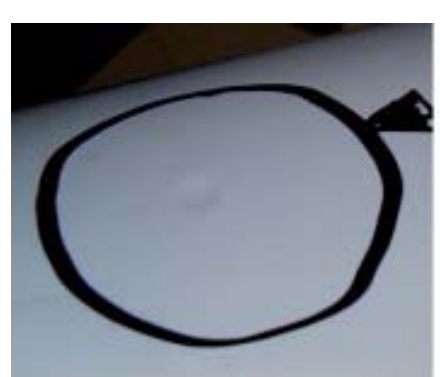

(a)

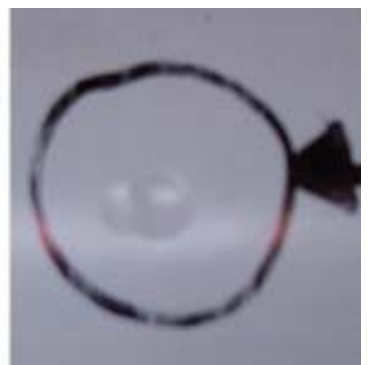

(b)
Fig. 12 Damage produced by impact: (a) $2 \mathrm{~m} / \mathrm{s}$ and (b) 4 $\mathrm{m} / \mathrm{s}$.

segment corresponds to the increasing slope of the pressure-time graph which is composed of two parts: the first one is the beginning of a non-lineal pressurization response, and the second is the lineal ramp until the desired test pressure (100 bar); once it is reached, the water pump supply is shutdown. From this point on, a pressure decrease of about 10 bar is observed due to small elongations on the pipe that produce small increments in volume, a type of behavior that can be attributed to a visco-elastic response of the polyethylene. The last segment corresponds to depressurization, with no remarks on its behavior.

\subsubsection{Load as a Function of Time}

Load is a response parameter to both pressure and 

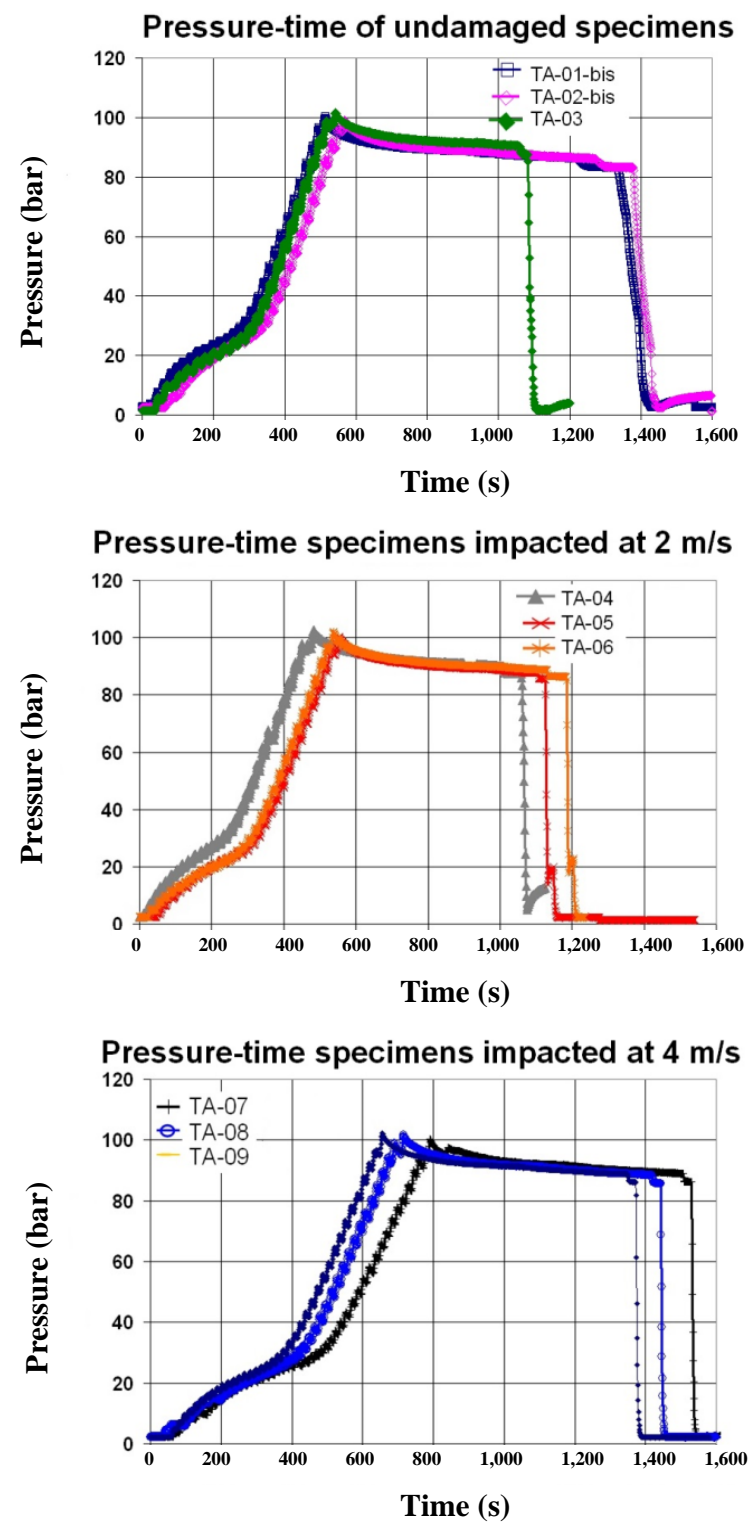

Fig. 13 Pressure profiles: (a) specimens without damage; (b) specimens impacted at $2 \mathrm{~m} / \mathrm{s}$ and (c) specimens impacted at $4 \mathrm{~m} / \mathrm{s}$.

the desired flexion displacement. In Fig. 14, an increase of the load can be observed at the beginning of the test because of a circumferential restrained expansion, due to the hydraulic pressure increase. Subsequently, a load augmentation is registered corresponding to the displacement of the actuator acting against the already pressurized bending pipe until the equivalent displacement of $1,500 \mathrm{~mm}$ bending radius is achieved with the three-point-bending test. On the top of the curve, there is a significant reduction
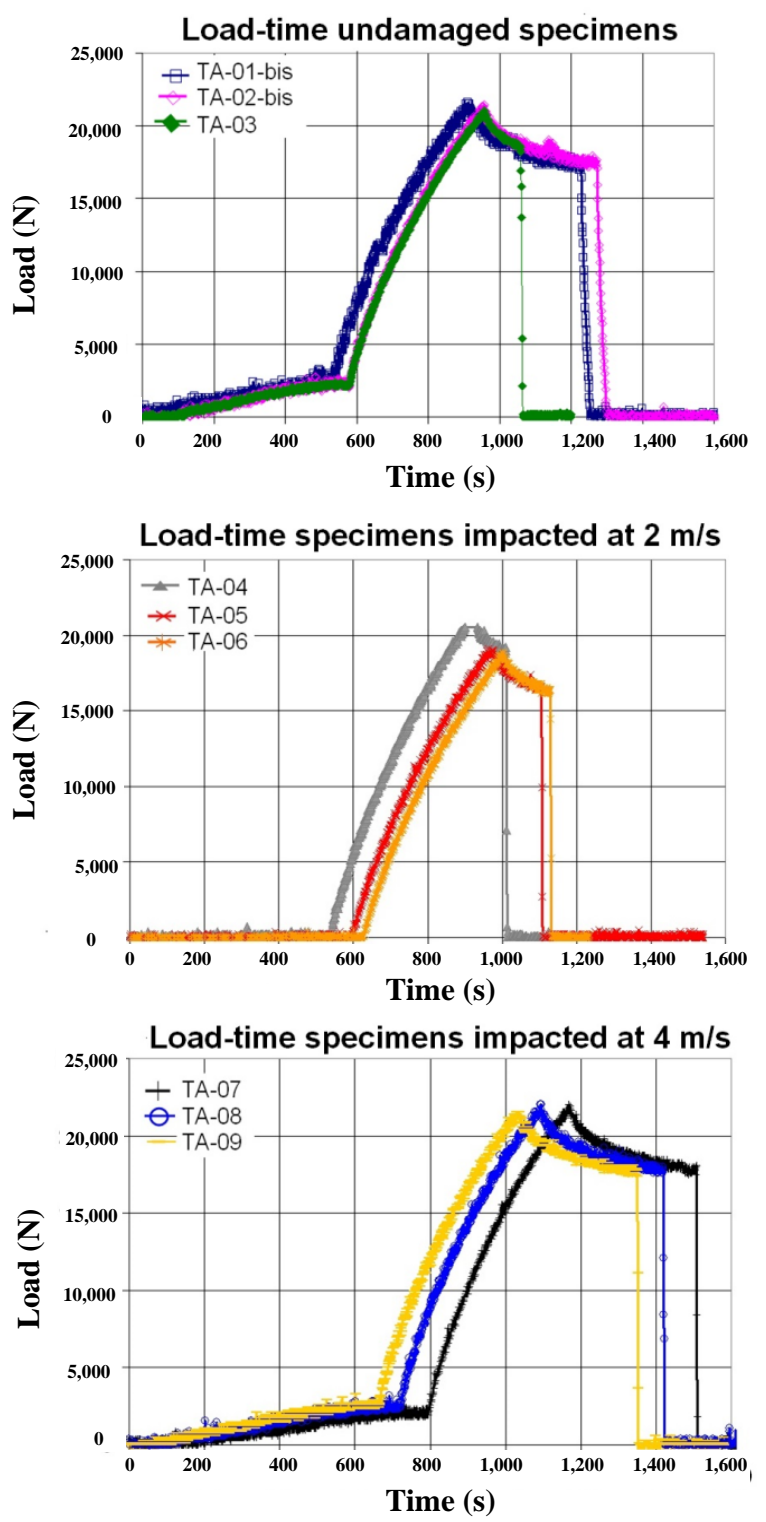

Fig. 14 Load profiles: (a) specimens without damage; (b) specimens impacted at $2 \mathrm{~m} / \mathrm{s}$ and (c) specimens impacted at $4 \mathrm{~m} / \mathrm{s}$.

of the load response due to the displacements within the pipe because of its visco-elastic behavior, typical of thermoplastic materials. The last segment corresponds to the flexural unloading.

Analyzing the graph load-time, the effect of the damages produced during impact test is imperceptible. Condensed values of the actual maximum pressure and load are presented in Table 2.

5.3.3 Load as a Function of Displacement

In Fig. 15, the load-displacement plot shows a 
Table 2 Maximum pressure and load.

\begin{tabular}{lll}
\hline Specimen & Maximum pressure (bar) & Maximum load (N) \\
\hline TA-01-bis & 100.2 & $21,601.3$ \\
TA-02-bis & 99.1 & $21,471.3$ \\
TA-03 & 101.8 & $21,063.7$ \\
TA-04 & 102.8 & $20,552.4$ \\
TA-05 & 100.3 & $19,084.5$ \\
TA-06 & 102.2 & $18,839.8$ \\
TA-07 & 100.3 & $22,020.5$ \\
TA-08 & 101.7 & $22,020.5$ \\
TA-09 & 102.3 & $21,531.2$ \\
\hline
\end{tabular}

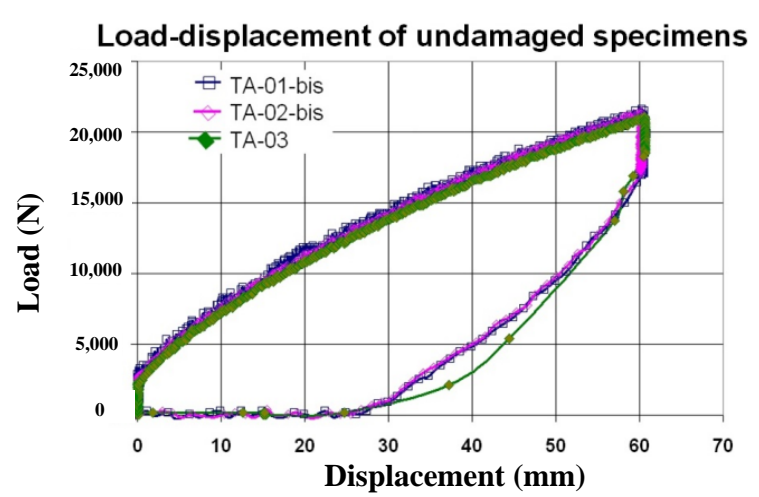

Load-displacement of specimens impacted at $2 \mathrm{~m} / \mathrm{s}$

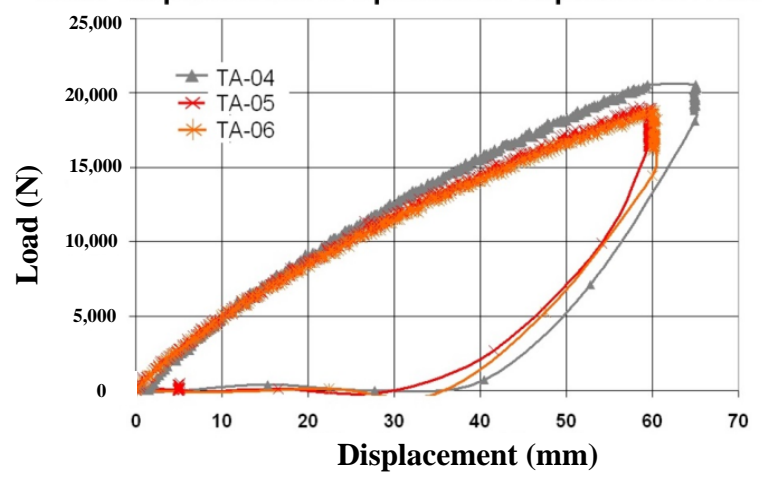

Load-displacement of specimens impacted at $4 \mathrm{~m} / \mathrm{s}$

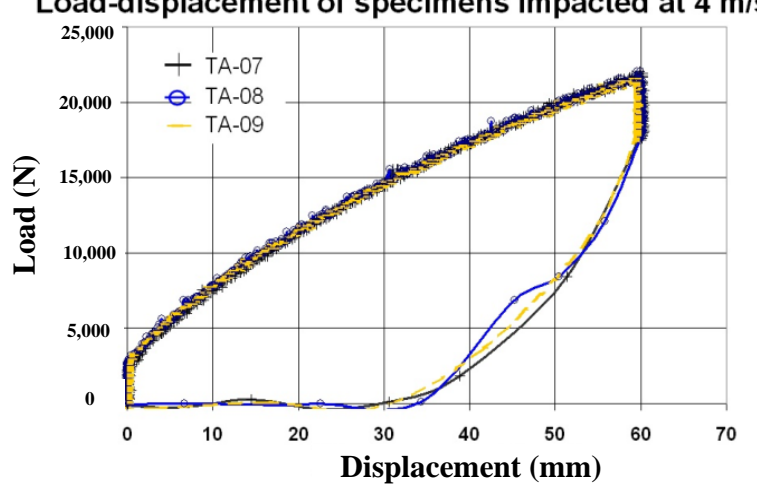

Fig. 15 Load versus displacement diagram: (a) specimens without damage; (b) specimens with a $2 \mathrm{~m} / \mathrm{s}$ impact and (c) specimens with a $4 \mathrm{~m} / \mathrm{s}$ impact. non-linear behavior followed by a permanent elongation after unloading; this behavior may be attributed to a visco-elastic response combined with plasticity. The plastic strain is in the order of magnitude of $25 \mathrm{~mm}$ for specimens without damage, and of $30 \mathrm{~mm}$ for specimens previously impacted.

\section{Conclusions}

Based on experimental observations, it can be stated that the tested specimens withstand the maximal operating pressure specified by the manufacturer (100 bar), as well as additional combined flexure load in the presence of damage, in this case as generated by a series of impacts that simulate either a pickaxe tool or a backhoe loader.

These tests show a global behavior of the product (the pipe as a whole structure), thus not representing only material properties.

The performed tests are complementary to those specified either on international standards or on local regulations/norms, and they can offer a better approach for design and analysis of pipes submitted to harsh conditions.

\section{Acknowledgments}

The authors gratefully thank IPN (Instituto Politécnico Nacional) faculty member Antonio Mosqueda Sánchez, as well as students Sergio Ávila Hernández, Renato Alcázar Morales, Diego Camarena Arellano, Daniel Hernández M., Alexander Morales Gómez and Honorio Ortiz Hernández for their collaboration and support.

\section{References}

[1] Kruijer, M. P., Warnet, L. L., and Akkerman, R. 2005. "Analysis of the Mechanical Properties of a RTP (Reinforced Thermoplastic Pipe).” Composites: Part A 36: 291-300.

[2] El-Assal, A. M., and Khashaba, U. A. 2007. "Fatigue Analysis of Unidirectional GFRP Composites under Combined Bending and Torsional Loads." Composite Structures 79: 599-605.

[3] Hur, S. H., Son, H. J., Kweon, J. H., and Choi, J. H. 2008. 


\section{Performance Quality Testing under Combined Loading of Polyethylene Pipes Reinforced with Aramid Fiber}

"Postbuckling of composite cylinders under external hydrostatic pressure.” Composite Structures 86: 114-24.

[4] Guedes, R. M. 2009. "Stress-Strain Analysis of a Cylindrical Pipe Subjected to a Transverse Load and Large Deflections." Composite Structures 88: 188-94.

[5] Lam, K. Y., Zong, Z., and Wang, Q. X. 2003. "Dynamic Response of a Laminated Pipeline on the Seabed Subjected to Underwater Shock." Composites Part B 34: 59-66.

[6] Weaver, P. M. 2003. "The Effect of Extension/Twist Anisotropy on Compression Buckling in Cylindrical Shells.” Composites Part B 34: 251-60.

[7] Krishnaswamy, R. K. 2005. "Analysis of Ductile and Brittle Failures from Creep Rupture Testing of HDPE
(High-Density Polyethylene) Pipes.” Polymer 46: 11664-72.

[8] Kruijer, M. P., Warnet, L. L., and Akkerman, R. 2006. "Modeling of the Viscoelastic Behaviour of Steel Reinforced Thermoplastic Pipes.” Composites Part A 37: 356-67.

[9] Alexander, C. 2007. "Evaluating the Use of Composite Materials in Reinforcing Offshore Risers Using Full-Scale Testing Methods.” Presented at the Conference ASME International Offshore Pipeline Forum, Texas, USA.

[10] Corona, E., and Kyriakides, S. 2000. "Asymmetric Collapse Modes of Pipes under Combined Bending and External Pressure.” Journal of Engineering and Materials 126: $1232-39$. 